\title{
TENDENCIAS EN INGENIERÍA DE MATERIALES PARA LA FABRICACIÓN DE CÉLULAS SOLARES FOTOVOLTAICAS
}

\author{
Oscar Giovanni Cucaita-Hurtado ${ }^{1}$, Iván Orlando Cabeza² \\ ${ }^{1}$ Ingeniero ambiental. Correo electrónico: oscarcucaita@usantotomas.edu.co \\ ${ }^{2}$ Ingeniero químico. Profesor \\ Universidad Santo Tomás, Bogotá, Colombia
}

Fecha de recibido: 5 de abril del 2017

Fecha de aprobado: 2 de agosto del 2017

Cómo citar este artículo: 0. G. Cucaita-Hurtado y I. 0. Cabeza, "Tendencias en ingeniería de materiales para la fabricación de células solares fotovoltaicas”, Ingeniería Solidaria, vol. 13, n. ${ }^{0}$ 23, pp. 151-162, Sept. 2017. doi: https://doi.org/10.16925/ in.v13i23.2070

Resumen: Introducción: el artículo de revisión fue desarrollado durante el segundo semestre del 2016 y el primero del 2017 en la Facultad de Ingeniería Ambiental de la Universidad Santo Tomás. La energía solar fotovoltaica ha adquirido un importante papel en el contexto global por el uso de fuentes renovables y disminución de impactos ambientales, además de ser un participe influyente en la satisfacción de la demanda energética actual. No obstante, esta cuenta con limitaciones como la dependencia de la disponibilidad de radiación y el uso de silicio como materia prima de las células solares. Metodología: se realizó un estado del arte de diferentes bases de datos consultadas, en su mayoría Science Direct y Scopus, sobre los diferentes materiales alternativos y tendencias actuales, y su perspectiva de funcionamiento e implementación. Resultados: se exponen las células solares que están empleando diversos materiales, dentro de las cuales destacan las de Teluro de Cadmio (CdTe) que presentan características de bajo costo y considerables eficiencias. Conclusión: las células de cobre, indio, galio, selenio/azufre (CIGS) presentan como característica principal el alto coeficiente de adsorción; no obstante, el gran reto por superar es llevar a cabo su implementación en un ámbito industrial. Las células solares orgánicas presentan una alta eficiencia y un bajo costo para su posible uso en el contexto colombiano.

Palabras clave: células orgánicas, células solares, eficiencia, energía solar, materiales fotovoltaicos. 


\title{
TRENDS IN MATERIALS ENGINEERING FOR THE MANUFACTURE OF PHOTOVOLTAIC SOLAR CELLS
}

\begin{abstract}
Introduction: This review article was written during the second half of 2016 and the first of 2017 at the School of Environmental Engineering, Universidad Santo Tomás. Photovoltaic solar energy has acquired an important role in the global context due to the use of renewable sources and the reduction of environmental impacts, as well as for being an influential participant in meeting the current energy demand. However, it has limitations such as dependence on the availability of radiation and the use of silicon as a raw material for solar cells. Methodology: We prepared a state of the art of different databases searched, mostly Science Direct and Scopus, on the different alternative materials and current trends and their perspective of operation and implementation. Results: The solar cells that are using different materials are presented, among which the Cadmium Telluride (CdTe) solar cells stand out for their low cost and considerable efficiencies. Conclusion: Copper, indium, gallium, selenium/sulfur (CIGS) cells are characterized mainly by their high adsorption coefficient; however, the great challenge to overcome is to implement them in an industrial environment. Organic solar cells are highly efficient and low-cost for their potential use in the Colombian context.
\end{abstract}

Keywords: organic cells, solar cells, efficiency, solar energy, photovoltaic materials.

\section{TENDÊNCIAS EM ENGENHARIA DE MATERIAIS PARA A FABRICAÇÃo DE CÉLULAS SOLARES FOTOVOLTAICAS}

Resumo. Introdução: o artigo de revisão foi desenvolvido durante o segundo semestre de 2016 e o primeiro de 2017 na Faculdade de Engenharia Ambiental da Universidade Santo Tomás. A energia solar fotovoltaica adquiriu um importante papel no contexto global pelo uso de fontes renováveis e diminuição de impactos ambientais, além de ser um participante influente na satisfação da demanda energética atual. Entretanto, essa conta com limitações, como a dependência da disponibilidade de radiação e o uso de silício como matéria-prima das células solares. Metodologia: foi realizado um estado da arte de diferentes bases de dados consultadas, em sua maioria, Science Direct e Scopus, sobre os diferentes materiais alternativos e tendências atuais e sua perspectiva de funcionamento e implementação. Resultados: expõe-se as células solares que estão empregando diversos materiais, dentro das quais destacam as células solares de Telureto de Cádmio (CdTe) que apresentam características de baixo custo e consideráveis eficiências. Conclusão: as células de cobre, índio, gálio, selênio/enxofre (CIGS) apresentam como característica principal o alto coeficiente de absorção; no entanto, seu grande desafio a ser superado é finalizar sua implementação em um âmbito industrial. As células solares orgânicas apresentam uma alta eficiência e um baixo custo para seu possível uso no contexto colombiano.

Palavras-chave: células orgânicas, células solares, eficiência, energia solar, materiais fotovoltaicos. 


\section{Introducción}

La energía solar representa una fuente principal de energía renovable, que tiene un impacto directo sobre los ciclos biofísicos, geofísicos y químicos. A pesar de que esta radiación se aprovecha en una pequeña proporción, la cantidad de radiación solar emitida resulta suficiente para la subsistencia de las condiciones físicas e interacciones que ocurren allí [1]. No obstante, en la actualidad, se tiene una problemática creciente en el tema energético por el uso de combustibles fósiles que tienen como consecuencia directa el incremento de los gases de efecto invernadero, el agotamiento de recursos y la contaminación atmosférica como causantes principales del calentamiento global [1]-[3]. Con el propósito de lograr un control de estas problemáticas conjuntas, se han llevado a cabo diversas investigaciones encaminadas hacia una búsqueda de nuevas alternativas energéticas, que consideren y empleen el flujo constante de esta energía solar percibida en la tierra. Para realizar un aprovechamiento de esta, existen dos tecnologías: la térmica, en la que se transforma la energía procedente del sol en energía calorífica, y la fotovoltaica, en la que se convierte directamente la energía solar en energía eléctrica por medio del efecto fotovoltaico [1], [4]-[7]. Esta última consiste en un conjunto de elementos, denominados células solares o fotovoltaicas, que son dispuestos en paneles, y logran la transformación de energía solar en energía eléctrica. La luz solar incidente transporta energía en forma de flujo de fotones, los cuales repercuten en determinados tipos de materiales, que bajo ciertas condiciones generan una corriente eléctrica. A esto se denomina el efecto fotovoltaico [1], [4 ], [5].

A pesar de la alternativa energética que se presenta con la fabricación de paneles solares fotovoltaicos (reducción de emisiones de $\mathrm{CO}_{2}$, fuente de energía inagotable, disminución de la dependencia energética por provenir de recursos autóctonos, sistemas de fácil instalación, instalaciones modulables entre otras) [8], estos cuentan con una serie de problemáticas que limitan su uso y desarrollo [1], [5]. Dentro de estas se identifican los materiales que componen las células solares, las cuales son el fundamento principal de los paneles. Estas células han sido fabricadas con base de un material específico, el cual es el silicio y por requerimientos de conductividad son dopados con otros elementos como el fósforo y el boro. Sin embargo, este material conlleva una serie de limitaciones, tales como el costo de inversión y eficiencia, ambientalmente poco sostenibles en cuanto a su proceso de fabricación [1], [5].

No obstante, actualmente se desarrollan investigaciones y estrategias encaminadas hacia la solución y búsqueda de alternativas que permitan superar los limitantes que presenta el uso convencional del silicio en los paneles solares fotovoltaicos [9]. Por medio del presente artículo, desarrollado por la Facultad de Ingeniería Ambiental de la Universidad Santo Tomás durante el $2 .^{\circ}$ semestre del 2016 y el $10^{\circ}$ del 2017, se describen los materiales de células solares de teluro de cadmio (CdTe), células cobre, indio, galio y selenio o azufre (CIGS), células orgánicas con heteruniones que están siendo tendencia, así mismo su funcionamiento, ventajas y desventajas, e impacto ambiental de estos tipos de células solares fotovoltaicas.

\section{Nuevos materiales para la fabricación de paneles solares fotovoltaicos}

Como se mencionaba anteriormente, las células solares convencionales a base de silicio presentan varias desventajas: una de las más significativas se justifica en la alteración ambiental que ocasiona la fabricación de paneles solares que usan silicio como materia prima. Según un análisis del ciclo de vida desarrollado para estos paneles, autores como el de [10] establecen que, dentro de este análisis, la fase de fabricación del panel solar es la de mayor impacto ambiental, principalmente debido a la obtención del silicio multicristalino, el cual es un proceso muy intensivo a nivel energético y con gran generación de corrientes residuales; además, los procesos que involucran al inversor, al vidrio solar y la metalización de la celda generan de igual forma un impacto considerable, sumándole el proceso de encapsulado y enmarcado, consecuente a una dimensión económica, en el cual el silicio para su obtención y proceso representa alrededor del $50 \%$ del coste total del módulo [10], [11]. Esta clara problemática que involucra las células solares de silicio puede ser afrontada y superada por medio de nuevas alternativas y desarrollos en el uso de materiales y procesos de fabricación de las células solares.

En ese orden de ideas, la tendencia actual, encaminada hacia la búsqueda y desarrollo de nuevos 
materiales para la fabricación de células solares, conjuga características generales, tales como la absorción de la luz solar, bajos costos de inversión, mayores rendimientos y desarrollos en los procesos de fabricación, y presenta alternativas sostenibles y de menor impacto para el medio ambiente. Una de las tendencias más dinámicas se ve reflejada en la fabricación de células solares de película delgada, en especial de materiales policristalinos de adsorción, como el teluro de cadmio (CdTe), el cobre indio galio diseleniuro (CIGs) y las denominadas células solares orgánicas OPV [5], [12]. Este tipo de materiales se describen a continuación.

\subsection{Células solares de teluro de cadmio de película delgada (CdTe)}

Inicialmente, es importante destacar que el teluro de cadmio (CdTe) se cataloga dentro del ámbito científico como un material prometedor para la obtención de altas eficiencias y bajo costo mediante su aplicación en las células solares de películas delgadas [13]. Considerando las diferentes técnicas de fabricación de las películas delgadas policristalinas de $\mathrm{CdTe}$, se reportan eficiencias que rondan el 15,8\% y el 22,1\% según los diferentes estudios [13]-[18].

El diseño de la presente célula se basa en lo que se denomina una configuración de sustrato, dentro del cual son depositados materiales activos, que a su vez actúan como una ventana transparente que logra permitir la radiación solar, la cual incide directamente dentro del dispositivo. Este sustrato es una hoja de vidrio que está cubierta con una película delgada de óxido de estaño dopado con flúor (FTO), el cual actúa como un óxido conductor transparente. La fabricación consiste en una deposición de capas de sulfuro de cadmio y teluro de cadmio (CdS/CdTe), las cuales llevan a cabo la conducción del contacto posterior. En este proceso se consideran procesos de sublimación de espacio cerrado, además de métodos químicos y electroquímicos [5], [19]. No obstante, cabe resaltar quelos óxidos conductores transparentes desempeñan un papel fundamental dentro de la eficiencia de las células solares de película delgada, ya que ofrece el denominado "contacto frontal", el cual permite que la radiación solar involucrada en la célula subyacente lleve la electricidad generada hacia el circuito externo; no obstante, este contacto frontal debe ser acoplado con muy baja resistencia eléctrica [20]. Esta célula puede proporcionar una respuesta espectral superior para climas húmedos y cálidos con un coeficiente de temperatura superior [17]. Por ejemplo, en temperaturas superiores a $25^{\circ} \mathrm{C}$, empresas como First Solar, que han venido trabajando y comercializando los módulos conformados por células de este material (CdTe), logran una producción mayor de energía, presentando medidas por módulo de 60 x $120 \mathrm{~cm}$ [17]. De esta manera, se ofrece hasta un $8 \%$ más de energía por parte de este tipo de módulos en comparación con el uso convencional de módulos de silicio cristalino [13], [17]. Las estructuras esquemáticas de las células de CdTe se ilustran en la figura 1.

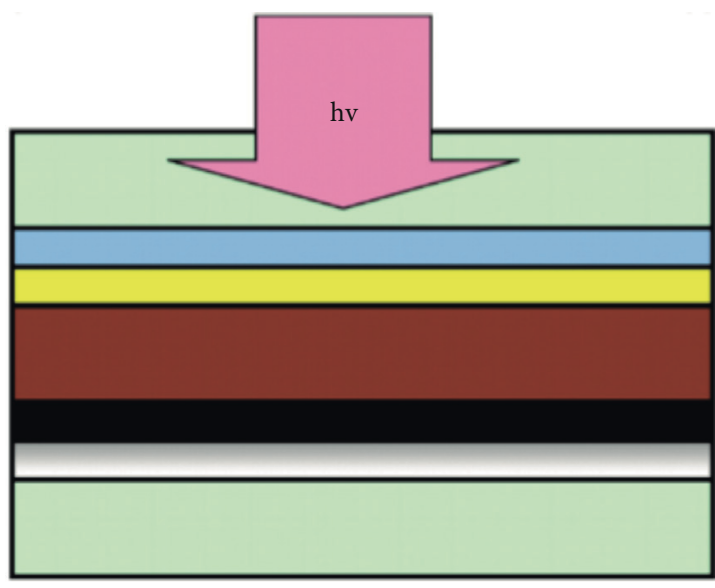

Figura 1. Sección transversal de la estructura típica de una célula solar tipo CdTe. La luz incide en la célula a través del sustrato de vidrio conductor. Vista de arriba hacia abajo: vidrio, FTO, CdS, CdTe, contacto óhmico, metalización y vidrio Fuente: [5]

Más allá de las eficiencias logradas, cabe resaltar que es necesario contemplar el análisis de ciclo de vida de los módulos solares fabricados en base de los diferentes compuestos, haciendo énfasis en el teluro de cadmio, el cual se considera perjudicial para la salud humana y se cataloga como peligroso [21]. Aun así, se presentan programas de disposición, reciclaje y de seguridad que permiten el control de este tipo de sustancias. Dado este caso, se afirma que este tipo de células solares y módulos permite lograr un reciclaje de un $90 \%$ del total de los elementos empleados, tales como el vidrio y los materiales semiconductores encapsulados, previos a ser llevados a su disposición final [17], [18], [22]. Además, a este nivel, la empresa estadounidense First Solar es la única que por ahora fabrica y comercializa módulos solares de teluro de cadmio en el ámbito industrial, considerando un precio de fabricación mucho menor en comparación 
con las células de silicio. Esto tiene también la ventaja dequeserequieremenos material paralageneración de una cantidad comparable de energía eléctrica frente a las células de silicio, hecho consecuente con un proceso de fabricación más sencillo [23].

\subsection{Células CIGS}

Estas células contemplan elementos como cobre, indio, galio y selenio o azufre dentro de las tecnologías fotovoltaicas, los cuales se afirman como los mejores materiales de absorción con eficiencias de tecnología de película delgada, y con valores de $22,3 \%$ a nivel de laboratorio y $16 \%$ en módulo comercial grande. De igual forma, este material atrae la investigación científica por su bajo costo, principalmente [24]. Además de su alto coeficiente de absorción, se afirma que solo 2 micras de espesor de película cigs pueden adsorber la mayor parte del espectro solar incidente. Así mismo, pequeñas cantidades de material se emplean para cubrir las células cigs mediante un depósito en un sustrato que puede ser rígido o flexible [25].

Actualmente, las células de tipo cIGs se fabrican por procesos de pulverización catódica o evaporación conjunta, dentro de la cual se lleva a cabo una reacción en atmósfera en selenio. Además, una de las tres etapas que conjugan coevaporación de los elementos $\mathrm{Cu}$, In, Ga y Se permite hacer una capa de CIGs, cuya característica principal es lograr la formación de una capa absorbedora [5], [26], [27]. Este tipo de células se componen de un electrodo trasero de molibdeno (Mo); una capa absorbedora de luz; un semiconductor $p$, que consiste en un compuesto de calcopirita $(\mathrm{Cu}(\mathrm{InGa}) \mathrm{Se} 2)$; un semiconductor $n$ de CdS $\mathrm{u}$ oxisulfuro de zinc $(\mathrm{Zn}(\mathrm{O}, \mathrm{S}))$; un contacto frontal, formado por una capa delgada de alta resistividad de óxido de zinc $(\mathrm{ZnO})$, y una capa transparente conductora de óxido de zinc dopado con aluminio ( $\mathrm{ZnO}: \mathrm{Al})$ [5]. El hecho de que su fabricación sea realizada por procesos de pulverización catódica ayuda a que sea aplicada no solo para sustratos rígidos (como vidrio), sino también sobre sustratos flexibles (como metales o polímeros). Esto lleva a obtener altos rendimientos, además de lograr una disminución considerable en costos, a lo que se suma una amplia integración estructural para su adaptación hacia todo tipo de superficies [5], [28]. La estructura de la célula se ilustra a continuación.

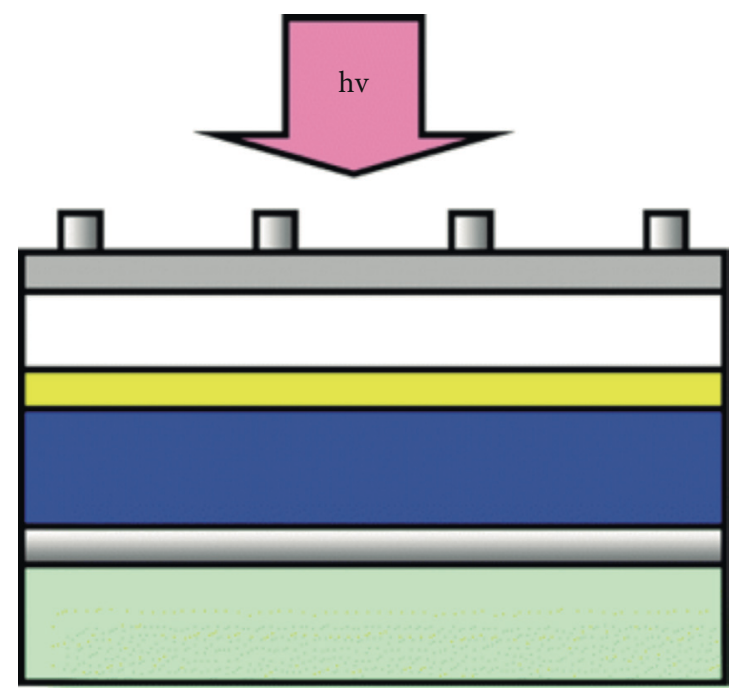

Figura 2. Sección transversal de la estructura de una célula solar de Cigs. La luz entra en la célula a través de la parte superior de contacto transparente $\mathrm{ZnO}$. De abajo hacia arriba: vidrio, molibdeno, CIGs, CdS, i-ZnO, Al:ZnO Fuente: [5]

Así mismo, se desarrollan investigaciones actuales de una nueva célula solar que conjuga los elementos de cigs y una doble unión de cobre-galioselenio (CGS) [29]. En este estudio se obtiene un rendimiento de una célula solar catalogada CGs/Cigs, el cual se estimula por medio del uso del software Silvaco Atlas para mejorar la estructura por medio de la optimización de las impurezas CGs y el ajuste de corrientes, que consigue una eficiencia máxima de conversión de energía del $43,05 \%$ y posibilita un diseño que ilustra un mejor rendimiento de conversión de energía [29].

No obstante, las células solares de cigs deben afrontar y superar una serie de retos con los cuales pueda hacer más accesible su implementación en el entorno de la energía solar fotovol.taica, dentro de los cuales se destacan aumentar la eficiencia de las células y módulos hasta su potencial máximo; lograr un menor consumo de materiales y energía en la fabricación de estos; obtener un desarrollo de integración monolítica, la cual es un tipo de circuito integrado con una gran cantidad de dispositivos microelectrónicos interactuados, diodos y transistores para los módulos solares, y uno de los más influyentes, es lograr una transferencia tecnológica de escala de laboratorio hacia una fabricación industrial [28], [30]. Además, en el contexto ambiental, esta célula conjuga elementos de cadmio e indio, los cuales 
son muy limitados o están presentes en pequeñas fracciones en la corteza terrestre y, considerando la creciente demanda energética, no se tendría una proyección prometedora en el abastecimiento de este tipo de células. Sin embargo, las continuas investigacioness se encaminan al reemplazo de este tipo de elementos [29], [31].

\subsection{Células orgánicas fotovoltaicas}

Dentro de este tipo de células solares se visualiza una amplia tendencia y proyección, cuyo fundamento primordial es el uso de polímeros que pueden ser empleados como semiconductores. Sus inicios parten de las investigaciones de científicos como el químico japonés Hideki Shirakawa [12], el físico estadounidense Alan Heeger [12] y el químico estadounidense Alan MacDiarmid [12], en las cuales se realizaron descubrimientos sobre las propiedades conductoras de cierto tipo de polímeros que lograron incidir fuertemente en la tecnología de dispositivos electrónicos y su gran desarrollo en el ámbito de la energía solar fotovoltaica [12]. En ese orden, un polímero semiconductor es una macromolécula que presenta unidades repetitivas llamadas monómeros, que, a diferencia de los polímeros tradicionales, son altamente conjugados, presentando orbitales, que garantizan tener cadenas de alta densidad electrónica con propiedades electrónicas únicas, comparables a semiconductores inorgánicos [12], [32]. Dentro de las células orgánicas fotovoltaicas, los materiales semiconductores orgánicos abarcan células de dos clases: pequeñas moléculas y compuestos poliméricos, las cuales tienen un modo diferente de preparación, purificación y fabricación del dispositivo. Así mismo, las pequeñas moléculas semiconductoras son procesadas a través de deposición de fase de vapor a alto vacío, mientras que los polímeros conductores son típicamente procesados a partir de disolventes orgánicos, lo cual incide en la morfología a nanoescala de películas delgadas que repercuten en gran medida sobre el rendimiento de la célula solar [33], [34].

Además, las células solares basadas en polímeros han logrado contemplar un amplio interés debido a la combinación de propiedades físicas y químicas variadas, tales como un peso ligero, sencilla procesabilidad y una adecuada flexibilidad mecánica, además de una fabricación de alto rendimiento logra una significativa reducción de costos y mejor desarrollo de las instalaciones fotovoltaicas [33], [35], [36].
En ese orden, el modelo inicial de una célula orgánica contemplaba una unión simple o una capa única de un polímero conjugado entre dos electrodos metálicos, cuya función principal es la generación de un campo eléctrico; sin embargo, la baja constante dieléctrica de los polímeros conjugados no permitía una eficiencia de conversión viable [3]. La estructura de una célula orgánica fotovol.taica se muestra en la figura 3.

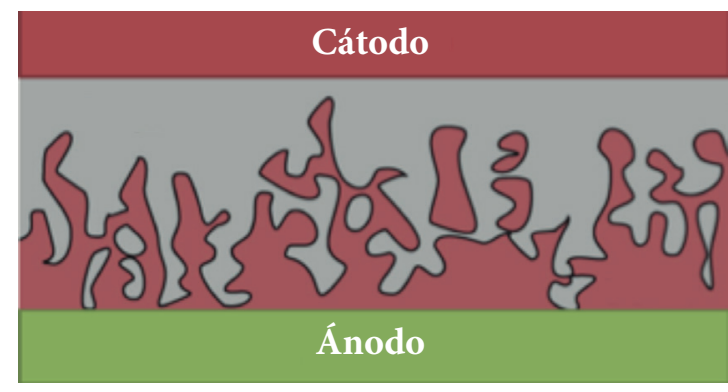

Figura 3. Sección transversal de una célula orgánica. Los electrones fotoinducidos y portadores de carga son generados en una interfaz entre el donor y el aceptor, y, a su vez, se transportan por medio de las fases aceptoras y donantes al cátodo y el ánodo, respectivamente Fuente: [5]

Este tipo de células muestran una proyección y un fuerte énfasis dentro de la energía solar fotovoltaica, y amplias investigaciones dan a conocer las diferentes alternativas que inciden en el desarrollo de este tipo de células. No obstante, a pesar de su fácil procesamiento y bajos costos de fabricación, y la abundancia de materiales orgánicos, así como su fácil manejo, las células solares orgánicas presentan eficiencias por debajo del límite teórico, con un valor porcentual del 23\% [37]. Otra desventaja de las células orgánicas fotovoltaicas, que influye a nivel general, es la susceptibilidad que estas presentan frente al oxígeno y el agua [38]. Aun así, la eficiencia de fotoconversión de células solares orgánicas puede verse mejorada considerando factores como la arquitectura de dispositivos, la optimización de estructuras moleculares de polímeros de tipo $p$, y la optimización de parámetros y condiciones pertenecientes a las capas de deposición en la estructura del dispositivo, lo que logra un incremento del $10 \%$ en la eficiencia [39]-[45]. 


\subsection{Células orgánicas fotovoltaicas de heterounión}

Este tipo de células toma como base configuraciones similares a de las células solares a base de compuestos inorgánicos. En esto, el concepto de heterounión o heterojuntura se aplica en estas células por su relación entre dos materiales con diferentes afinidades electrónicas y potenciales de ionización. Entre otros términos, se puede definir como una sobreposición o interpenetración de compuestos o capas [12]. Los dispositivos fotovoltaicos orgánicos, basados en los materiales donantes de electrones y aceptores, son una fuerte vía para lograr la conversión de fotones a corriente como una alternativa mayoritariamente económica en comparación de las células solares de silicio tradicionales [46].

Dentro de estas células, el primer paso para generar fotocorriente es lograr la formación de excitones por medio de la absorción de fotones en la mayor parte de los dispositivos [43], [46]. Dado esto, el campo eléctrico para separar los portadores en la interfaz se crea de acuerdo a los diferentes orbitales moleculares ocupados, el más alto (номо) o potencial de ionización (PI) y orbitales moleculares desocupados más bajos (LUMO), o afinidad electrónica (ЕA) de los donantes y receptores [46], [47]. En la figura 4 se muestra un diagrama que comprende las bandas de energía del material donor y aceptor, dentro del cual se observa que en las células solares orgánicas con heterounión, la adsorción de fotones (a) por parte de la capa activa, donde se genera una transición electrónica entre los estados homo y lumo del material donor, se genera un sistema de pares de electrón-hueco conocidos como excitones (b), y estos a su vez se localizan en la estructura del compuesto. Los excitones generados se difunden hasta la interfaz con el material aceptor, dentro del cual se disocian y generan portadores de cargas libres (c) cuyo movimiento es independiente a través de cada material, hasta finalizar en los contactos eléctricos (d) [12]. Unas de las heterouniones de gran campo investigativo son las denominadas bulkheterjunction (BHJ; en español, células solares de heterounión de polímero a granel), que prometen una perspectiva para su desarrollo debido a ventajas como costos bajos, flexibilidad de la célula, peso ligero y capacidad de procesamiento simple [48]. En ello, se han observado eficiencias de conversión de potencia o de fotoconversión para este tipo de células que han alcanzado un 11,7\% [48]-[50].

Sin embargo, estas células cuentan con principales factores limitantes como la estrecha absorción de luz y la restricción en la generación de carga. Aún así, se afirma que múltiples mezclas ternarias de materiales fotoactivos para la formación de células solares son una estrategia sencilla para resolver dichas limitaciones [51], [52].
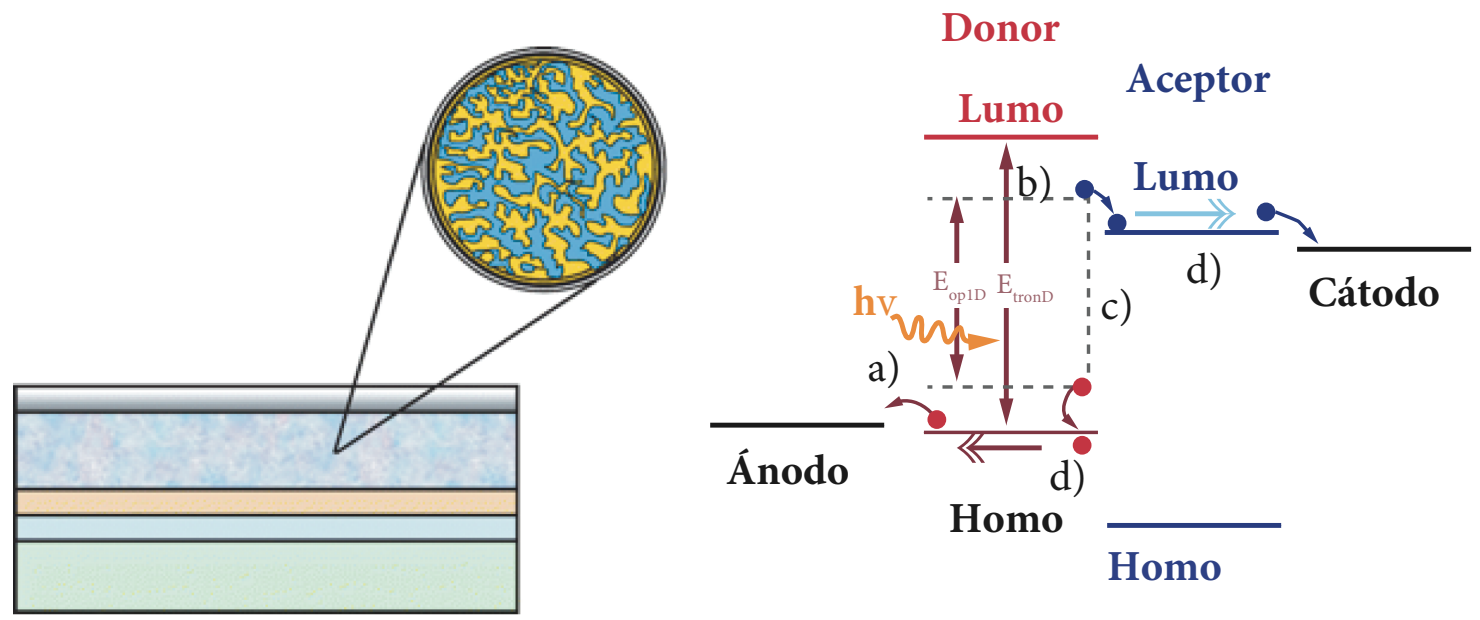

Homo

Figura 4. Sección transversal de una célula orgánica izquierda. De abajo hacia arriba: vidrio, estructuras de óxido de indio y estaño, poli(3,4-etilendioxitiofeno), poli(estirenosulfonato) (РЕDот), Р3Нт (tiofeno poli-3-hexil) y aluminio. Derecha: proceso interno de la capa adsorbente de una célula solar orgánica Fuente: [5] y [16] 
Este tipo de heterojunturas (BHJ) consiste en una mezcla de poli(3-hexiltiofeno) como donante de electrones y 6,6-fenil $\mathrm{C}_{61}$ ester metílico del ácido butírico como aceptor de electrones [53], [54]. Además, una correcta organización y estructuración de materiales donante y aceptor permite limitar la recombinación del electrón-hueco mediante la generación de una separación de fases, dentro de la cual, el tamaño característico es equivalente a la longitud de difusión del excitón. En ese orden de ideas, resulta importante el control de la morfología de la mezcla Р3НТ/РСВм [53].

No obstante, se ha enfatizado en diversos trabajos en el uso de copolímeros en bloque (formados por macromoléculas constituidas por bloques poliméricos en una secuencia lineal) [55] como donor/aceptor por su compatibilidad en la mezcla Р3НT/РCBM. Estos son empleados como estrategia para el control de la morfología y, con ello, aumentar la estabilidad de los dispositivos; además, se ha demostrado que la adición de donante-aceptor de copolímero en bloques de Р3HT-b (bisimida acrilato de perileno)-poli se emplea como un compatibilizador [53], [56], [57].

En cuestiones de rendimiento, se evidencian diferentes correlaciones de factores que influyen directamente, así como su interrelación. En la figura 5, se muestran los aspectos fundamentales en el tema del rendimiento. Un claro ejemplo de esta relación es la constitución química de cada uno de los componentes, puesto que afirma su función y su forma de interacción con los demás materiales, su capacidad de ordenamiento u orientación en la estructura cristalina de este, la morfología de la capa activa y la estructura electrónica, que condicionan de manera directa la eficiencia y rendimiento del dispositivo [58], [59].

Dado el caso, investigaciones actuales han tenido fuerte énfasis dentro del factor morfológico que contempla a su vez, las mezclas de donante-aceptor o copolímeros en bloques cuyo objetivo principal es equilibrar el transporte de carga y lograr una mayor adsorción de la luz, y en las que se han caracterizado cuatro tipos de morfologías que se han empleado en la capa activa de las células solares orgánicas, las cuales siguen siendo objeto de estudio [58]-[63].

Actualmente se llevan a cabo investigaciones sobre el mejoramiento y desarrollo de este tipo de células. Se contemplan dispositivos fotovoltaicos orgánicos ternarios que se prepararon de acuerdo a pequeñas cantidades de metaloporfina-tertiofen en

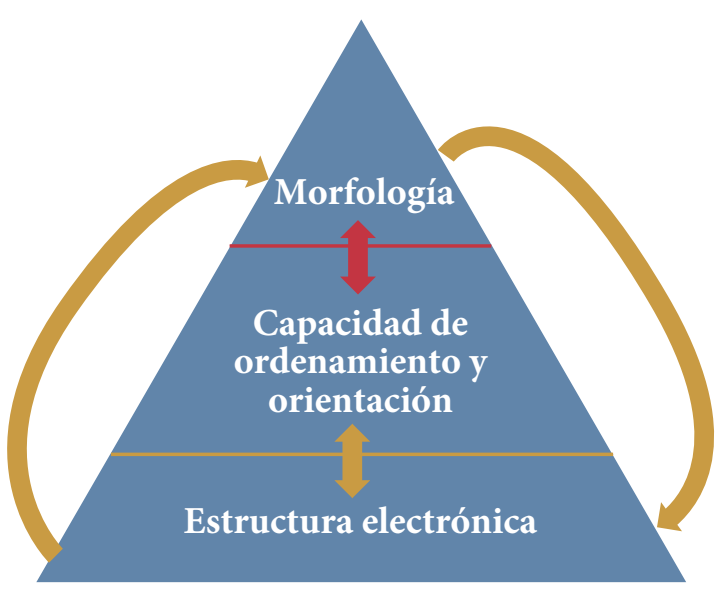

Figura 5. Pirámide de correlación que involucra el rendimiento del dispositivo en células $\mathrm{BHJ}$ Fuente: [59]

las mezclas de fullereno, la cual repercute de manera directa en la eficiencia de conversión de energía del dispositivo, con un valor inicial del $5,1 \%$, que a su vez condujo un aumento del $16 \%$, resultados que se compararon con otra mezcla binaria. Además, entre las cantidades aplicadas de metaloporfinas, se encuentra que el $\mathrm{Cu}$ (II) porfirina aplicado en la mezcla desarrolla una mejora significativa en la eficiencia [64].

En términos generales, las células orgánicas fotovoltaicas presentan ciertas características y ventajas que abarcan el componente ambiental, pues se afirma que son células con menor impacto ambiental, considerando procesos de fabricación, materiales empleados y análisis de ciclo de vida. De forma más específica, se muestran las ventajas en términos ambientales en cuanto al menor gasto energético para su fabricación, además de que los materiales resultantes después de cumplir su ciclo de uso pueden ser removidos con solventes orgánicos o agua en algunos casos, con lo cual dichas células ofrecen una ventaja y mejor viabilidad para llevar a cabo el tratamiento y la disposición final de los residuos generados [65].

\section{Discusión}

Pese a los diferentes materiales expuestos, sigue existiendo un impacto ambiental considerable tomando como base el análisis de ciclo de vida de estos materiales y sus limitantes en términos de 
eficiencias, según las eficiencias de fotoconversión registradas. Desde luego, los aspectos mencionados son dependientes del proceso de fabricación contemplando los materiales y procesamientos de estos para la fabricación de paneles. Actualmente, tanto el mercado como la demanda energética generan una apertura positiva para promover la implementación de paneles solares fotovoltaicos como medida contribuyente; no obstante, es ambiguo centralizar un material ideal como prospección de dicha implementación, más si se toma en análisis un aspecto fundamental como el rendimiento, además de que las células solares de silicio, según lo expuesto, pueden y deben ser reemplazables por los factores mencionados. En ello, los nuevos materiales que son tendencia siguen siendo objeto de estudios para promover su implementación con los mecanismos más favorables en términos ambientales y de eficiencias de fotoconversión.

\section{Conclusiones}

Las investigaciones actuales parten del propósito de superar los limitantes que presentan las células solares de silicio, haciendo énfasis en aspectos como la disminución de costos para llevar a cabo la implementación de paneles solares, la obtención de mayores rendimientos y eficiencias de fotoconversión, y la disminución de los impactos ambientales causados durante todo el ciclo de vida de un panel solar fotovoltaico. Según lo explicado en el artículo, cada uno de los nuevos materiales expuestos otorgan consideraciones que superan los limitantes mencionados y mejoras de algunos de los aspectos; no obstante, es consecuente la presencia de inconvenientes que restringen su desarrollo e implementación en el ámbito industrial

Las células de teluro de cadmio, por ejemplo, mediante el uso de películas delgadas, tienen una respuesta espectral mejor, en especial en climas cálidos húmedos; además, una vez culminado el ciclo de vida del panel cuyas células están compuestas de CdT, se logra un porcentaje de reutilización del 90\% de los materiales (no se considera el reciclaje del CdT por su peligrosidad e impacto ambiental causado), característica que no presentan las células cigs. Además, el indio es un elemento poco frecuente en la corteza terrestre y resulta esencial para el funcionamiento de estas células solares.
En comparación con las células orgánicas, estas proveen mayores beneficios, dados principalmente por la disposición y degradación de sus materiales debido al uso de materiales orgánicos durante el ciclo de vida de estos paneles.

Las células CIGs presentan valores que alcanzan un $22 \%$ de rendimiento, similar a las células CdT y superior a las orgánicas. No obstante, este valor representa una simulación en laboratorio y no un valor concreto llevado en el ámbito industrial, como sí lo representan las células CdT y orgánicas.

Estas últimas centralizan la expectativa en la nueva tendencia y futuro de paneles solares fotovoltaicos, mediante el uso de materiales orgánicos para su funcionamiento. A pesar de que su rendimiento es mucho menor frente a las células de CdT y CIGs, aspectos como los costos de implementación e impacto ambiental ocasionado por funcionamiento son menores en una gran proporción, lo que permite tener una perspectiva científica encaminada hacia el desarrollo de este tipo de células. Adicionalmente, estas investigaciones pretenden mejorar el rendimiento y eficiencia de fotoconversión mediante los materiales orgánicos empleados (tipos de polímeros) y las conjugaciones o compenetraciones entre estos, así como mejorar la flexibilidad y eficacia de la película delgada que las compone. En ese orden, a nivel investigativo, las células más apropiadas que permitan el reemplazo y mejora del uso convencional de células solares de silicio son las orgánicas, según la tendencia científica consultada.

\section{Referencias}

[1] C. E. Marín, "La energía solar fotovoltaica", Nimbus, n. ${ }^{\circ} 13-14$, pp. 5-31, 2004. [Online]. Disponible en https://dialnet.unirioja.es/descarga/articulo/1173549. pdf

[2] A. L. N. M. I. Millán y P. A. R. Aumente, "Investigación e impacto ambiental de los edificios. La Energía", Inf. La Construcción, vol. 57, n. ${ }^{\circ}$ 1, pp. 47-61, 2005. [Online]. Disponible en http://informesdelaconstruccion.revistas.csic.es/index.php/informesdelaconstruccion/article/view/477

[3] F. Bellenilla, "La sostenibilidad desde la perspectiva del agotamiento de los combustibles fósiles, un problema socio-ambiental relevante", Investigación en la Escuela, vol. 55, pp. 73-87, 2005. [Online]. doi: https://doi.org/10.3989/ic.2005.v57.i498.477 
[4] L. Bird et al., "Wind and solar energy curtailment: A review of international experience", Renew. Sustain. Energy Rev, vol. 65, pp. 577-586, 2016. [Online]. doi: https://doi.org/10.1016/j.rser.2016.06.082

[5] L. M. Peter, "Towards sustainable photovol.taics: the search for newmateriales", Philos. Trans. A. Math. Phys. Eng. Sci., vol. 369, n..$^{\circ} 1942$, pp. 140-1856, 2011. [Online]. doi: https://doi.org/10.1098/rsta.2010.0348

[6] I. B. Salbidegoitia García, "Energía Solar", DYNA, vol. 83, n. ${ }^{\circ}$ 9, pp. 561-566, Dic. 2008. [Online]. Disponibleen https://es.scribd.com/document/325763315/2411DYNAINDEX-pdf

[7] E. Lorenzo, "Retratos de la conexión fotovoltaica a la red (Iv) seguidores y huertas solares", Era Sol., vol. 119, n. $^{\circ}$ IV, pp. 6-23, 2004. [Online]. Disponible en www.fotovoltaica.com/retrato6.pdf

[8] Madridsolar, Guía de la energía solar. Madrid: Madridsolar, 2006. [Online]. Disponible en https:// www.fenercom.com/pdf/publicaciones/guia-de-laenergia-solar-fenercom.pdf

[9] C. E. L. Latunussa, F. Ardente, G. A. Blengini y L. Mancini, "Life Cycle Assesment of an innovative recycling process for crystalline silicon photovoltaic panels", Sol. Energy Mater. Sol. Cells, vol. 146, pp. 101111, 2016. [Online]. doi: https://doi.org/10.1016/j. solmat.2016.03.020

[10] O. Enguita, "Análisis del ciclo de vida para el desarrollo de las Reglas de la Categoría de Producto de sistemas solares fotovol.taicos para la edificación", Universitat politécnica de Catalunya, 2012. [Online]. Disponible en https://upcommons.upc.edu/bitstream/ handle/2099.1/19179/TFM-OscarEnguita.pdf

[11] J. Del Río et al., "Análisis del ciclo de vida de un panel solar fotovoltaico empleado para la alimentación eléctrica de instalaciones de riego, comparando las metodologías eco-indicador 99 y EPs-2000", presentado en XIII Congreso Nacional de Ciencias Hortícolas, Almería, 2012, pp. 708-712.

[12] W. A. Chamorro Coral y S. Urrego Riveros, "Celdas solares orgánicas, una perspectiva hacia el futuro", Elementos, vol. 2, n.o 2, May. 2013. [Online]. doi: http://dx.doi.org/10.15765/e.v2i2.181

[13] B. W. Han, S. C. Park, J. H. Ahn y B. T. Ahn, "Photovoltaic properties of close-space sublimated $\mathrm{CdTe}$ solar cells", Sol. Energy, vol. 64, n. ${ }^{\circ} 1-3$, pp. 49-54, 1998. [Online]. doi: https://doi.org/10.1016/S0038092X(98)00023-1

[14] T. L Chu, S. S. Chu, C. Ferekides, C.Q. Wu, J. Britt y C. Wang, "13,4\% efficient thin-film CdS/CdTe solar cells”, J. Appl. Phys., vol. 70, n. ${ }^{\circ}$ 12, 1991. doi: https:// doi.org/10.1063/1.349717

[15] M. A. Green, K. Emery, Y. Hishikawa, W. Warte y E. D. Dunlop, "Solar cell efficiency tables (version 41)",
Prog. Photovoltaics Res. Appl., vol. 21, n. ${ }^{\circ} 1,2013$. [Online]. doi: https://doi.org/10.1002/pip.2352

[16] M. A. Green, K. Emery, Y. Hishikawa, W. Warte y E. D. Dunlop, "Solar cell efficiency tables (version 40)", Prog. Photovoltaics Res. Appl., vol. 20, n. ${ }^{\circ}$ 5, 2012. [Online]. doi: https://doi.org/10.1002/pip.2267

[17] President's Advisory Council on Financial Literacy, "Annual Report", 2008. [Online]. Disponible en https:// www.treasury.gov/about/organizational-structure/ offices/Domestic-Finance/Documents/exec_sum.pdf.

[18] E. Regalado-Pérez, M. G Reues-Banda y X. Mathew, "Influence of oxygen concentration in the $\mathrm{CdCl} 12$ treatment process on the photovol.taic properties of CdTe/CdS solar cells", Thin Solid Films, vol. 582, pp. 134-138, 2015. [Online]. doi: https://doi.org/10.1016/j.tsf.2014.11.005

[19] A. K. Turner et al. "Stable, high efficiency thin film solar cells produced by electrodeposition of cadmium telluride", Sol. Energy Mater., vol. 23, n. ${ }^{\circ}$ 2-4, pp. 388-393, 1991. [Online]. doi: https://doi. org/10.1016/0165-1633(91)90145-B

[20] S. J. C. Irvine et al., "The role of transparent conducting oxides in metal organic chemical vapour deposition of CdTe/CdS Photovol.taic solar cells". Thin Solid Films Filmes, vol. 515, n. ${ }^{\circ}$ 15, pp. 6.099-6.102, 2007. [Online]. doi: http://dx.doi.org/10.1016/j. tsf.2011.04.194

[21] S. Arroyo, B. Ortiz, L. Enrique y C. Vicentina. "Cadmio: efectos sobre la salud. Respuesta celular y molecular", Acta Toxicológica Argentina, vol. 21, pp. 33-49, 2013. [Online]. Disponible en https://documentslide. org/cadmio-efectos-sobre-la-salud-respuesta-celular-y-molecular

[22] J. Sites y J.Pan, "Strategies to increase CdTe solar-cell vol.tage", Thin Solid Films, vol. 515, n. ${ }^{\circ} 15$, pp. 6.0996.102, 2007. [Online]. doi: https://doi.org/10.1016/j. tsf.2006.12.147

[23] R. Martin, "Células solares de teluro de cadmio logran un nuevo récord de eficiencia", MIT Technol. Rev., 2016. [Online]. Disponible en https://www.technologyreview.es/s/5648/celulas-solares-de-teluro-de-cadmio-logran-un-nuevo-record-de-eficiencia

[24] J. M. Delgado-Sánchez et al., "Front contact optimization of industrial scale cis solar cells for low solar concentration using 2D physical modeling", Renew. Energy, vol. 101, pp. 90-95, 2017. [Online]. doi: https://doi.org/10.1016/j.renene.2016.08.046

[25] M. Saifulah et al., "Effect of $\mathrm{Cu}$ content on the photovol.taic proprieties of wide bandgap CIGS solar cells for low solar concentration using 2D physical modeling" Renew. Energy, vol. 101, pp. 90-95, 2017. [Online]. doi: https://doi.org/10.1016/j.renene.2016.08.046 
[26] Y. M. Shin, C. S. Lee, D. H. Shin, H. S. Know, B. G. Park y B. T. Ahn, "Surface modification of cigs film by annealing and its effect on the band structure and photovol.taic properties of CIGs solar cells", Curr. Appl. Phys., vol. 15, n. ${ }^{\circ}$ 1, pp. 18-24, 2015. [Online]. doi: https://doi.org/10.1016/j.cap.2014.09.023

[27 Y. M. Shin, D. H. Shin, J. H. Kim y B. T. Ahn, "Effect of $\mathrm{Na}$ doping using $\mathrm{Na} 2 \mathrm{~S}$ on the structure and photovol. taic properties of cigs solar cells", Curr. Appl. Phys., vol. 11, n. ${ }^{\circ}$ 1, Supplement, pp. S59-S64, 2011. [Online]. doi: https://doi.org/10.1016/j.cap.2010.11.019

[28] J. Gutiérrez Berasategui y E, Barriga, “Tecnología Cigs para nuevas células solares”, Energías renovables, p. 4, 2012. [Online]. Disponible en https:// www.energias-renovables.com/fotovoltaica/tecnologia-cigs-para-nuevas-celulas-solares

[29] B. Farhadi and M. Naseri, "Structural and physical characteristics optimization of a dual junction CGS/sigs solar cell: A numerical simulation", Optik (Stuttg), vol. 127, n. ${ }^{\circ}$ 21, pp. 1032-10237, 2016. [Online]. doi: https://doi.org/10.1016/j.ijleo.2016.08.029

[30] J.T. Horstmann y K. F. Goser, "Monolithic integration of a silicon micromotor in combination with the cmos drive circuit on one chip", Microelectron. Eng., vol. 67-68, pp. 390-306, 2003. [Online]. doi: https://doi.org/10.1016/S0167-9317(03)00094-7

[31] N. Espinosa y F.C Krebs, "Life cycle analysis of organic tandem solar cells: When are they warranted?" Sol. Energy Mater. Sol. Cells, vol. 120, n. ${ }^{\circ}$ PART B, pp. 692-700, 2014. [Online]. doi: https://doi. org/10.1016/j.solmat.2013.09.013

[32] F. Martinez et al., "Classical or inverted photovoltaic cells: On the importance of the morphology of the organic layers on their power conversion efficiency", Dyes and Pigments, vol. 132, pp. 185193, 2016. [Online]. doi: https://doi.org/10.1016/j. dyepig.2016.04.050

[33] F. Meyer, "Fluorinated conjugated polymers in organic bulk heterojunction solar cells", Prog. Polym. Sci., vol. 47, pp. 70-91, 2015. doi: https://doi.org/10.1016/j.progpolymsci.2015.04.007

[34] Y. Hunag, E. J. Kramer, A. J. Heeger y G.C. Bazan, "Bulk heterojunction solar cells: Morphology and performance relationships", Chem. Rev., vol. 114, n. ${ }^{\circ}$ 14, pp. 7.006-7.043, 2014. [Online]. doi: https://doi. org/10.1021/cr400353v

[35] Y. Guo et al., "Polymer solar cells with high open-circuit vol.tage based on novel barbell-shaped bifullerene derivative as acceptor", Chinese J. Chem., vol. 36, n. ${ }^{\circ}$ 1, pp. 172-178, 2016. [Online]. doi: https://doi. org/10.6023/cjoc201506012

[36] D. Gendron y M. Lecler, "New conjugated polymers for plastic solar cells", Energy Environ. Sci., vol. 4, n. ${ }^{\circ}$ 4, pp. 1225-1237, 2011. [Online]. doi: https://doi. org/10.1039/c1ee01072g

[37] T .E. Anderson y M. E Kose, "Impact of solution casting temperature con power conversion efficiencies of bulk heterojunction organic solar cells", J. Photochem. Photobiol. A Chem., vol. 318, pp. 51-55, 2016. [Online]. doi: https://doi.org/10.1016/j.jphotochem.2015.11.026

[38] G. Chidichimo y L. Filipelli, "Organic solar cells: Problems and perspectives", Int. J. Photoener$g y$, vol. 2010, 2010. [Online]. doi: http://dx.doi. org/10.1155/2010/123534

[39] T. E. Anderson and M. E. Kose, "Impact of solution casting temperature on power conversion efficiencies of bulk heterojunction organic solar cells", J. Photochem. Photobiol. A Chem., vol. 318, pp. 51-55, 2016. [Online]. doi: https://doi.org/10.1016/j.jphotochem.2015.11.026

[40] T. Fukua, H. Suzuki, N. Yoshimoto y Y. Liao, "Controlled donor-acceptor ratio for application of organic photovoltaic cells by alternative intermittent electrospray co-deposition", Org. Electron., vol. 33, pp. 32-39, 2016. [Online]. doi: https://doi. org/10.1016/j.orgel.2016.03.011

[41] I. Etxebarria, J. Ajuria y R. Pacios, "Solution-Processable polymeric solar cells: A review on materials, strategies and cell architectures to overcome 10\%”, Org. Electron. Physics, Mater. Appl., vol. 19, pp. 34-60, 2015. [Online]. doi: https://doi.org/10.1016/j. orgel.2015.01.014

[42] A. Pivrikas, H. Neugebauer y N. S. Sariciftci, "Influence of processiong additives to nano-morphology and efficiency of bulk-heterojunction solar cells: A comparative review", Sol. Energy, vol. 85, n. ${ }^{\circ}$ 6, pp. 1.226-1.237, 2011. [Online]. doi: https://doi.org/10.1016/j.solener.2010.10.012

[43] P. Peumans, A Yakimov y S. R Forrest, "Small molecular weight organic thin-film photodetectors and solar cells", J. Appl. Phys., vol. 93, n. ${ }^{\circ}$ 7, pp. 3693-3723, 2003. [Online]. doi: https://doi.org/10.1063/1.1534621

[44] S. S. Sun, "Optimum energy levels and offsets for organic donor/acceptor binary photovol.taic materials and solar cells", Mater. Sci. Eng. B Solid-State Mater. Adv. Technol., vol. 116, n. ${ }^{\circ}$ 3, pp. 251-256, 2005. [Online]. doi: https://doi.org/10.1016/j.mseb.2004.05.052

[45] S. Sun et al., "Conjugated block copolymers for opto-electronic functions", Synth. Met., vol. 137, n. ${ }^{\circ}$ 1-3, pp. 883-884, 2003. doi: https://doi.org/10.1016/ S0379-6779(02)01124-4

[46] B. Pradhan y A. J. Pa, "Organic heterojunction photovoltaic cells: Role of functional groups in electron acceptor materials", Sol. Energy Mater. Sol. Cells, vol. 
81, n. ${ }^{\circ} 4$, pp, 469-476, 2004. [Online]. doi: https:// doi.org/10.1016/j.solmat.2003.11.024

[47] T.Stübingery W. Brütting, "Exciton diffusion and optical interference in organic donor-acceptor photovoltaic cells", J. Appl. Pys., vol. 90, n. ${ }^{\circ}$ 7, pp. 3632-3641, 2001. doi: https://doi.org/10.1063/1.1394920

[48] Q. An et al., "Improved efficiency of bulk Heterojunction Polymer Solar Cells by Doping low bandgap small molecule", Acs Appl. Mater. Interfaces, vol. 186, Agos. 2016, pp. 161-164, 2014. [Online]. doi: https://doi.org/10.1016/j.matlet.2016.09.118

[49] H. Zhao et al., "Efficient organic solar cells processed from hydrocarbon solvents", Nat. Energy, vol. 1, pp. 15-27, 2016. doi: https://doi.org/10.1038/ nenergy.2015.27

[50] A. Kovalenko et al., "Towards imporved efficiency of bulk-heterojunction solar cells using various spinel ferrite magnetic nanoparticles", Org. Electron., vol. 39, pp. 118-126, 2016. doi: https://doi.org/10.1016/j. orgel.2016.09.033

[51] P. Fan, Y. Zhng, D. Zheng y J. Yu, "Improved efficiency of bulk heterojunction polymer solar cells by doping with iridium complex", Mater. Left, vol. 186, pp. 161-164, 2017. doi: https://doi.org/10.1016/j. matlet.2016.09.118

[52] L. Lu, T. Xu, W. Chen, E.S Landry y L. Yu, “Ternary blend polymer solar cells with enhanced power conversion efficiency", Nat.Photonics, vol. 8, n. ${ }^{\circ}, 9$, pp. 716-722, 2014. doi: https://doi.org/10.1038/nphoton. 2014.172

[53] A. Mhamdi, W. Boukhili, M. Raissi, M. Mahdouani, L. Vignau y R. Bourguiga, "Simulation and optimization of the performance of organic photovoltaic cells based on capped copolymers for bulk heterojunctions", Supertattices Microstruct., vol. 96, pp. 241252, 2016. [Online]. doi: https://doi.org/10.1016/j. spmi.2016.05.029

[54] C. J. Brabec, "Organic photovol.taics: Tecnology and market", Sol. Energy Mater. Sol Cells, vol. 83, n. ${ }^{\circ}$ 2-3, pp. 273-292, 2004. [Online]. doi: https://doi.org/10.1016/j.solmat.2004.02.030

[55] R. C. Pasquali, D. A. Chiappetta y C. Bregni, "Los copolímeros en bloques anfitílicos y sus aplicaciones farmacéuticas", vol. 24, n. ${ }^{\circ} 4$, 2005. [Online]. Disponible en www.latamjpharm.org/trabajos/24/4/ LAJOP_24_4_7_2_GZNEXU4ZPK.pdf

[56] N. Sary et al., "A new supramolecular route for using rod-coil block copolymers in photovol.taic applications", Adv. Mater., vol. 22, n. ${ }^{\circ}$ 6, pp. 763 -
768, 2010. [Online]. doi: https://doi.org/10.1002/ adma.200902645

[57] C. Yang, J. K. Lee, A. J Heeger y F. Wild, "Well-defined donor acceptor rod-coil diblock copolymers based on P3HT containing C60: The morphology and role as a surfactant in bulk-heterojunction solar cells", J. Mater. Chem., vol. 19, n. ${ }^{\circ}$ 30, pp. 5416 5423, 2009. [Online]. doi: https://doi.org/10.1039/ b901732a

[58] F. Lui, Y. Gu, X. Shen, S. Ferdous, W. Wang y T. P. Russel, "Characterization of the morphology of solution-processed bulk heterojunction organic photovoltaics", Prog. Polym. Sci., vol. 38, n. ${ }^{\circ} 12$, pp. 1990-2052, 2013. [Online]. doi: https://doi.org/10.1016/j.progpolymsci.2013.07.010

[59] F. Lui, Y. Gu, J. W. Jung, W. H. Jo y T. P. Russell, "On the morphology of polymer-based photovoltaic”, J. Polym. Sci. Part B Polym. Phys., vol. 50, n. ${ }^{\circ}$ 15, pp. 1018-1044, 2012. [Online]. doi: https://doi. org/10.1002/polb.23063

[60] L. M. Chen, Z. Hong, G. Li y Y. Yango, "Recent progress in polymer solar cells: Manipulation of polymer: Fullerene morphology and the formation of efficient inverted polymer solar cells", Adv. Mater., vol. 21, n. ${ }^{\circ}$ 14-15, pp. 1434-1449, 2009. [Online]. doi: https:// doi.org/10.1002/adma.200802854

[61] K. M. Coakley and M. D Mc Gehee, "Conjugated polymer photovol.taic cells”, Chem. Mater., vol. 16, n. ${ }^{\circ} 23$, pp. 4533-4542, 2004. [Online]. doi: https://doi. org/10.1021/cm049654n

[62] M. A Ruderer, E. Metwalli, W. Wang, G. Kaune, S.V Roth y P, Müller-Buschbaum, "Thin films of photoactive polymer blends", Chem. Phys. Chem., vol. 10, n. ${ }^{\circ}$, pp. 664-671, 2009. [Online]. doi: https://doi. org/10.1002/cphc.200800773

[63] H. Hoppe and N. S. Sariciftci, "Morphology of polymer/fullerene bulk heterojunction solar cells", J. Mater. Che. M., vol. 16, n. ${ }^{\circ} 1$, pp. 45-61, 2006. [Online]. doi: https://doi.org/10.1039/B510618B

[64] D. M Stoltzfus et al., "Improved efficiency of polymer-fullerene bulk heterojunction solar cells by the addition of $\mathrm{Cu}(\mathrm{II})$-porphyrin-oligothiophene conjugates", Synth. Met., vol. 218, pp. 1-8, 2016. [Online]. doi: https://doi.org/10.1016/j.synthmet.2016.04.026

[65] A. L. Fagua y W. F. Bernal, "Celdas solares orgánicas, Revista Ciencia, Innovación y Tecnología, vol. 2, pp. 71-81, 2015. [Online]. Disponible en www.revistasjdc.com/main/index.php/rciyt/article/view/412 


\section{Pautas para autores}

\author{
http://ingenieriasolidaria.ucc.edu.co
}

\section{Propósito y alcance}

La revista Ingeniería Solidaria es una publicación académica que tiene por objetivo divulgar artículos de investigación, reflexión y revisión en las ingenierías (sistemas, industrial, electrónica, civil, materiales, minas, química, mecánica) y en educación en ingeniería. Su público objetivo son investigadores, grupos y semilleros de investigación, profesores y estudiantes de ingeniería en Colombia y otros países.

\section{¿Por qué Ingeniería Solidaria?}

El primer número de Ingeniería Solidaria se lanzó en el 2005 con el propósito de socializar a la comunidad científica la producción académica y la investigación en las ingenierías, bajo el auspicio de la Facultad de Ingeniería de la Universidad Cooperativa de Colombia. Como la Universidad Cooperativa fue creada bajo la filosofía de la economía solidaria y del cooperativismo, Ingeniería Solidaria quiso apropiarse del sentido de esos principios para darle una personalidad, un carácter a la revista, buscando no solo un impacto en el ámbito académico sino contribuyendo a divulgar experiencias, iniciativas, proyectos en ingeniería, que puedan tener un impacto local o en la región.

\section{Tipos de artículos}

De acuerdo con los requisitos de calidad académica para la indexación de las revistas colombianas (Índice Bibliográfico Nacional - Publindex), Ingeniería Solidaria busca, principalmente, la publicación de los siguientes tipos de artículos:

Artículo de investigación científica y tecnológica. Documento que presenta, de manera detallada, los resultados originales de proyectos terminados de investigación.

Artículo de reflexión derivada de investigación. Documento que presenta resultados de investigaciones ya terminadas y publicadas en otras revistas académicas desde la perspectiva analítica, interpretativa o crítica de quien escribe el artículo de reflexión, sobre un tema específico, recurriendo a fuentes originales.

Artículo de revisión. Documento resultado de una investigación terminada en el que se analizan, sistematizan o integran los resultados de investigaciones publicadas sobre un campo en ciencia o tecnología, con el fin de dar cuenta de los avances y las tendencias de desarrollo. Se caracteriza por presentar una cuidadosa revisión bibliográfica de por lo menos 50 referencias.

Adicionalmente, Ingeniería Solidaria contempla la publicación de ensayos, en los que se espera que se presente una reflexión articulada sobre algún tema de interés en ingeniería, así como artículos cortos (avances de investigación) y reportes de caso (resultados de experiencias técnicas y metodológicas, con una breve revisión de la literatura).

\section{Reseñas y espacio estudiantil}

Ingeniería Solidaria recibirá la postulación de reseñas críticas sobre monografías, artículos, libros de investigación y difusión científica en ingenierías que puedan ser de interés para los lectores de la revista o proponer alguna discusión sobre un tema vigente alrededor de la literatura del área.

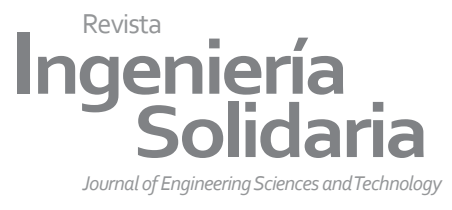

En el proceso de selección del material de cada número, la revista podrá considerar la publicación de un artículo estudiantil (nivel de pregrado), principalmente si se deriva de una investigación de tesis. Ese artículo debe ajustarse a los parámetros de presentación de la revista, además de venir acompañado del concepto de un profesor experto en la temática. La revista se reservará el derecho de aceptar o no el artículo, o de solicitar alguna revisión adicional externa para decidir sobre su publicación.

En el espacio estudiantil también podrán publicarse ensayos que resulten seleccionados de concursos o de eventos académicos nacionales en los que participe la revista.

\section{Políticas editoriales y pautas de presentación}

Originalidad. Todos los artículos o reseñas que se sometan al proceso de arbitraje de la revista Ingeniería Solidaria deben ser inéditos. Solicitamos a los autores abstenerse de remitir trabajos que ya han sido publicados parcial o completamente por otros medios -salvo publicaciones en línea de documentos de trabajo (working papers)- o en traducciones a otros idiomas. Si se detectan evidencias de documentos similares o idénticos ya publicados, el trabajo será rechazado automáticamente. Para verificar su originalidad, todo artículo o reseña postulado será sometido a un software de antiplagio.

Sistema de arbitraje. Todos los artículos que se presenten a la revista para sus ediciones serán sometidos a un proceso de arbitraje "doble ciego" que se realizará con ayuda de pares expertos en cada temática. La participación de los pares será ad honórem y se espera que sea asumido como un pacto de reciprocidad académica, en el que se intenta aportar de manera constructiva a fortalecer (y validar) la investigación y los aportes de otros colegas dentro de la disciplina. En el caso de las reseñas, que son documentos de difusión, podrán ser revisadas por el editor mismo o por otros miembros del equipo editorial de la revista. Su publicación se decidirá de acuerdo con su coherencia temática y textual, su relevancia para el área o según el interés o vigencia de la discusión que proponga.

Exclusividad. Los artículos que se sometan a arbitraje en Ingeniería Solidaria no pueden estar siendo evaluados por otras revistas, ni deben presentarse de manera simultánea a otros procesos de arbitraje.

Confidencialidad. Como el arbitraje se realizará a través de un sistema "doble ciego", con el fin de garantizar una mayor independencia de las partes (ni los autores ni los evaluadores tendrán entre sí datos de su identidad, perfil académico o procedencia), esa información solo será tratada por los responsables de la revista y no se revelará a terceras partes. Los soportes del proceso de cada artículo se conservarán para efectos de indexación o verificación del arbitraje.

Perfil de evaluadores. Los pares de Ingeniería Solidaria tendrán como mínimo formación de maestría y producción escrita publicada en el área en la que sean convocados a evaluar.

Periodicidad. Ingeniería Solidaria tiene una frecuencia cuatrimestral (enero, mayo y septiembre). La revista también editará números temáticos especiales por iniciativa del editor, 
integrantes de los comités o de colaboradores externos, y su publicación podrá realizarse en un número extraordinario (adicional) dentro del volumen (las condiciones o particularidades de las ediciones especiales serán divulgadas a través de un Call for papers específico).

Estructura de los artículos. La estructura básica de un artículo consta de lo siguiente: título, resumen, palabras clave, cuerpo del texto (que puede variar de acuerdo con el tipo de artículo y la intención del autor) y listado de referencias. Los detalles que un autor debe tener en cuenta al momento de alistar su artículo para Ingeniería Solidaria, están descritos de manera más extensa en una plantilla que se ha desarrollado para tal fin.

Propósito y coherencia. Se espera que todos los artículos que se postulen a Ingeniería Solidaria tengan un propósito explícito y que en ese sentido busquen una contribución que sea del interés del público lector de la revista. De igual forma, más allá de la posible estructura por la que el autor decida organizar los contenidos de su artículo (reseña o ensayo), se espera que los textos sigan un esquema coherente, en el que estén implícitos tres elementos esenciales: introducción, desarrollo articulado del tema y cierre.

Ética. La revista y su equipo editorial propiciarán, a través de sus políticas y actuaciones, la ética en los procesos de investigación, el uso apropiado de los contenidos protegidos por derechos de autor y la calidad de los trabajos que publica, de manera que los diferentes colaboradores (editores, autores y evaluadores) interactúen bajo principios de integridad académica.

Autores. Se espera que los autores que participen en la revista presenten textos originales, de su propia creación, derivados de procesos de investigación rigurosos, que no hayan sido previamente publicados, usen de manera adecuada las fuentes que sirven de soporte bibliográfico y cualquier otro material que esté protegido por derechos de autor. Los textos también deben estar escritos de manera cuidadosa y considerando los requisitos de forma y citación que correspondan al estilo de la revista.

Evaluadores. Se espera que los evaluadores de la revista realicen una lectura minuciosa y constructiva de cada artículo que acepten revisar, buscando no solo emitir una recomendación de aprobación o rechazo para el editor, sino que sus comentarios permitan que los autores mejoren sus textos o reflexionen sobre los alcances, posibilidades o falencias de su manuscrito. Asimismo, los evaluadores deben considerar que los textos que el editor les ha confiado son inéditos, y cualquier uso indebido o no autorizado de la información allí contenida implicaría una falta ética grave. También, la responsabilidad de evaluar un trabajo, una vez se ha aceptado, no puede ser transferida a terceros, en especial, si no se ha justificado y consultado previamente con el editor. Finalmente, cualquier conflicto de intereses que el evaluador identifique después de haber recibido un trabajo y que potencialmente menoscabe su independencia en la elaboración de un concepto debe informarse.

Notificación sobre casos. Si hay alguna evidencia de problemas éticos en las investigaciones que presentan los trabajos publicados por la revista, dudas sobre su rigor científico, sospecha de falsificación o manipulación indebida de datos, conflictos de intereses no revelados, identificación de publicaciones previas ("refritos"), problemas de autoría o plagio, pedimos, por favor, que se contacte de manera inmediata al editor de la revista para que pueda ahondar en el caso y tomar las acciones que correspondan. Las notificaciones que se reciban sobre problemas éticos se manejarán con absoluta confidencialidad, protegiendo la identidad de la persona que ha detectado el problema, si así lo solicita.

Retractaciones, correcciones y resolución de conflictos. La revista sigue los lineamientos (http://publicationethics.org/resources/guidelines) y procedimientos (http://publicationethics. org/resources/flowcharts) del Committee on Publication Ethics (COPE) para el manejo de conductas inapropiadas en la publicación académica. Asimismo, se harán retractaciones o correcciones de artículos ya publicados cuyos contenidos presenten errores que afecten su calidad científica o el reconocimiento apropiado de sus autores, ya sea por equivocaciones involuntarias en el proceso de investigación y publicación o por problemas éticos serios como plagio, falsificaciones, manipulaciones de datos, entre otros.

Uso de los contenidos y autoarchivo. La revista publica sus contenidos en acceso abierto, sin que medie ningún periodo de embargo. Asimismo, todos los trabajos publicados aparecen bajo una licencia Creative Commons de Reconocimiento-NoComercial-SinObraDerivada 4.0 Internacional (http://creativecommons.org/licenses/by-nc-nd/4.0/), y su uso debe hacerse bajo esas condiciones de licenciamiento.

Por otro lado, los autores pueden autoarchivar sus trabajos en repositorios institucionales, en la versión final (o versión del editor) en la que fue publicada el artículo, siempre y cuando se registren los datos bibliográficos de la publicación original del artículo, dando así crédito a la revista. Adicionalmente, al momento de autoarchivar un artículo publicado, es recomendable que los autores incluyan un enlace al artículo, a través de su DOI, de manera que pueda ser consultado en el sitio web oficial de la revista. Un papel activo por parte de los autores para difundir sus trabajos publicados entre colegas, estudiantes de pregrado y posgrado y entre la comunidad académica en general es clave para que se dé una contribución más efectiva en la disciplina o se produzca un mayor impacto en procesos de investigación y formación académica.

Costos de publicación. El envío de trabajos a la revista y su proceso de edición, en caso de que sean aprobados, es gratuito; no tiene ningún costo, en ninguna fase para los autores. La revista es financiada en su totalidad por el Fondo Editorial de la Universidad Cooperativa de Colombia.

Preservación digital de los contenidos. El Fondo Editorial garantizará la preservación digital de los contenidos que se publiquen, de manera que los autores puedan siempre recuperar sus artículos en el tiempo y mantener el acceso a lo que ha sido la historia y evolución de la revista.

Extensión. Se sugiere que los artículos tengan una extensión mínima de cuatro mil palabras (4000) y máxima de ocho mil (8000). Las reseñas críticas no deben superar las mil quinientas palabras (1500).

Envío. Las propuestas de artículos deben enviarse en formato Word, ajustando el texto a la plantilla sugerida por la revista y únicamente por vía electrónica. Junto con el artículo, cada uno de los autores debe remitir una ficha de autor completamente diligenciada y una carta de originalidad y compromiso ético. El archivo original y sus adjuntos deben remitirse a la atención del editor de la revista y al correo electrónico: ingenieriasolidaria@ucc.edu.co. Las reseñas también se recibirán únicamente por medio electrónico y en la plantilla requerida. 


\section{Estilo de citación: IEEE}

Los estilos de citación permiten presentar de manera organizada el soporte bibliográfico en el que se fundamenta un texto (en sus antecedentes, argumentos, metodología, entre otros), y facilitan la localización y consulta directa de esas fuentes. En el caso de Ingeniería Solidaria, se han seleccionado los estándares diseñados por el Institute of Electrical and Electronics Engineers, asociación conocida por la sigla de IEEE ("i triple e") y que son de común uso en publicaciones del área de las ingenierías.

A continuación, se detallan algunos aspectos que hay que considerar para el correcto uso de las normas del IEEE y de las particularidades que incorpora la revista.

Cuerpo del texto. Aunque no es necesario en las normas IEEE mencionar al autor(es) cuando se hace una referencia en el cuerpo del texto, la revista Ingeniería Solidaria, para evitar confusiones gramaticales o de redacción, prefiere que en la mayoría de los casos se mencionen los apellidos de los autores de los cuales se están tomando ideas, y después se inserte entre corchetes el número de la referencia completa que debe aparecer en el listado final del artículo. Por ejemplo: "Ortiz [1] presenta una metodología para el análisis de problemas matemáticos.” A propósito, todas las referencias que se incorporen en el cuerpo del texto deben relacionarse en la lista de referencias del final del artículo. Igualmente, en el listado de referencias no debe aparecer bibliografía que no se haya usado y citado en el texto (es decir, la correspondencia entre ambas partes debe ser exacta). Las referencias que se vayan incorporando en el texto se deben numerar por orden de aparición entre corchetes - Ortiz [1], Grothendieck [2], Gómez [3] - , y deben organizarse de esa forma en el listado final, no por orden alfabético. Por último, si una misma referencia se usa varias veces en el cuerpo del texto, pero es necesario incorporar nueva información sobre el apartado del texto al que se refiere o alguna otra particularidad, se debe indicar luego del número de la referencia, así: "Ortiz [1, p. 84] u Ortiz [1, Fig. 16]".

Listado de referencias. El listado de referencias debe organizarse por orden numérico que se determina de acuerdo con la aparición de cada referencia en el texto (el primer autor o texto que se cita es el número [1], el segundo el [2] y así sucesivamente). A diferencia de otros estilos, como no hay una organización alfabética de las referencias por apellido, los nombres de los autores deben registrarse comenzando por las iniciales y luego el apellido: “[2] A. Grotendieck,". A continuación, mostraremos el esquema de cómo se debe citar un libro, un capítulo de libro y un artículo de revista, con algunos ejemplos para cada caso:

\section{Libro}

[\#]Iniciales del nombre. Apellido, Título del libro en cursivas. Ciudad: Editorial, año, pp. (rango de páginas consultadas).

Ejemplo: [1] R.H. Ballou, Businees Logistics: Supply Chain Management. New York: Prentice Hall, 2003, pp. 250 - 300.

\section{Capítulo de libro}

[\#]Iniciales del nombre. Apellido, "Título del capítulo", en Título del libro, número de la edición. Nombre del editor, Ed. Ciudad: Editorial, año, rango de páginas.

Ejemplo:[1] R. Anderson, "Access control", en Security Engineering, $2^{\text {nd }}$ ed. New York: Wiley, pp. 93-128.

\section{Artículo de revista}

[\#]Iniciales del nombre. Apellido, "Título del artículo", Título de la revista (abreviatura), vol., n. ${ }^{\circ}, \mathrm{pp}$. (rango de páginas del artículo), abreviación del mes. Año.

Ejemplo: [1] S. Zhang, C. Zhu, J. K. O. Sin y P. K. T. Mok, "A novel ultrathin elevated channel low-temperature poly-Si TFT", IEEE Electron Device Lett, vol. 20, pp. 569-571, nov. 1999.

Si desea o necesita conocer algunos ejemplos adicionales para citar otro tipo de textos, por favor, póngase en contacto con el editor de la revista o consulte directamente la página de IEEE (IEEE style manual), en el siguiente enlace: http://www.ieee.org/ publications_standards/publications/authors/authors_journals. html

\section{Aspectos gráficos y otras particularidades}

Ecuaciones, gráficos, tablas y figuras. Las expresiones matemáticas deben hacerse con un editor de fórmulas adecuado. Los símbolos especiales se definirán cuando aparezcan por primera vez, bien sea en figuras, tablas o en el texto. Cada tabla, figura o gráfico debe indicar su fuente (o si es de elaboración propia), señalando la referencia con el número correspondiente. Las gráficas, figuras y tablas deben suministrarse siempre en un formato editable (se sugiere Excel). En el caso de las fotografías o imágenes, deben enviarse en una resolución mínima de 350 dpi, extensión .jpg, y los autores deben certificar que cuentan con los permisos para usarlas o reproducirlas.

Nomenclatura. Se utilizará el sistema internacional de unidades (sIu) y los símbolos correspondientes. En disciplinas en que la práctica corriente consiste en emplear el sistema métrico técnico (con fuerza en kilogramos) se podrá usar este sistema, pero en tal caso las cantidades irán seguidas por su equivalente sIU puesto entre paréntesis. En aquellas en que se acostumbren otras unidades, estas irán entre paréntesis, a continuación de su equivalente en el sistema siu.

\section{Proceso de arbitraje de artículos}

Como ya se ha descrito, Ingeniería Solidaria seguirá un sistema de arbitraje "doble ciego" para evaluar y decidir sobre la publicación de sus artículos principales. A continuación se ofrece una relación más detallada de las etapas en las que se desarrolla el arbitraje:

Recepción y evaluación editorial. Una vez el editor reciba la postulación del artículo, se remitirá una notificación al autor confirmando la entrega. Luego, el editor hará una revisión preliminar del artículo con el fin de establecer si se han cumplido cabalmente los parámetros de presentación de la revista y si el artículo corresponde a la línea temática y editorial. El editor tendrá completa potestad de decidir si el artículo podrá aceptarse para un proceso completo de arbitraje o si se debe rechazar en primera instancia. También, en esta fase, podrá devolver el manuscrito a los autores solicitando algunas correcciones o aclaraciones antes de que el artículo sea registrado oficialmente para el arbitraje. En caso tal, los autores deben regresar el artículo con ajustes (o la documentación que se haya omitido, por ejemplo, la ficha de autor o la carta de compromiso) si desean continuar con el proceso.

Selección de pares. Si el artículo es aceptado para arbitraje, el editor iniciará el proceso de asignación de revisores, localizando 
y convocando a dos investigadores expertos en el tema del artículo, que recibirán el texto completo del artículo y un formato que guiará su evaluación.

Tiempos de la evaluación. El tiempo usual de la localización y aceptación de los pares puede oscilar entre una (1) y tres (3) semanas, de acuerdo con el tema del artículo y la disposición de los pares que se convoquen. Una vez recibidos los artículos, los plazos sugeridos para la entrega de una evaluación es de tres (3) a cuatro (4) semanas, no obstante, los plazos se pactarán directamente con cada evaluador, considerando su disponibilidad de tiempo (y velando por que el proceso se desarrolle de la manera más eficiente posible).

Resultados. El editor enviará un resultado a los autores basándose en el concepto de al menos dos pares. En el caso de un conflicto en la opinión de los pares (una aprobación y un rechazo), se convocará a un tercer revisor antes de que el editor comunique una decisión a los autores. El resultado de la evaluación puede ser de "aprobado sin modificaciones", "aprobado con modificaciones menores", "aprobado con modificaciones sustanciales" o "rechazado". El concepto de "aprobado con modificaciones sustanciales" se asimila a "revise and resubmit", lo que implica una disposición de los autores de efectuar un replanteamiento profundo de la propuesta. De lo contrario, la revista dará por concluido ese proceso de arbitraje dejando en libertad a los autores de someter el trabajo a otra publicación.

Correcciones. Junto con el envío de un resultado, si el editor estima que es viable recibir una versión ajustada de un artículo, se pactará con los autores un plazo de entrega de la nueva versión que puede oscilar entre dos (2) hasta diez (10) semanas, en caso de un ajuste sustancial. Si los autores incumplen los plazos pactados, el editor podrá dar por terminado el proceso del artículo, descartando su publicación en la revista. Por otra parte, para facilitar una verificación de la versión ajustada, los autores deben modificar su artículo haciendo uso de la herramienta de control de cambios de Word, además de enviar una carta dirigida a cada evaluador, en la que se expliquen los ajustes efectuados. Sin la entrega de esa réplica a los evaluadores, el editor no enviará el artículo ajustado a la fase de verificación.

Verificación y versión final. La verificación en la mayoría de las ocasiones será efectuada con ayuda de los pares, pero también el editor podrá revisar directamente los ajustes hechos en el artículo, si las correcciones han sido menores. De tal modo, en caso de que se soliciten ajustes leves para un artículo, se pide a los autores que se abstengan de incorporar cambios de fondo o que impliquen un ajuste conceptual o metodológico, que no haya sido verificado por los evaluadores. Por otro lado, si los ajustes han sido satisfactorios, el editor informará a los autores de la aprobación y solicitará la presentación de la versión final del artículo en una plantilla en la que será remitido a producción editorial. Si en el proceso de alistar la versión final se detecta algún error de importancia que implique corregir o modificar el artículo en algún sentido sustancial, se debe informar al editor.

\section{Producción editorial}

Los artículos y los diferentes tipos de textos que se aprueben para publicación en un número de Ingeniería Solidaria serán sometidos a un proceso de producción editorial profesional que consta de las siguientes etapas: corrección de estilo, diagramación, cotejo de pruebas, verificación, y aprobación de artes finales.
Los autores deben entregar el manuscrito que fue aprobado para publicación en una plantilla que facilitará la revista, cerciorándose de cumplir cabalmente con todas las instrucciones allí suministradas. Adicionalmente, los autores tienen la responsabilidad de atender las observaciones, dudas o correcciones que surjan en la edición, dentro de los tiempos concretos que se pacten y con el fin de evitar retrasos en la publicación.

Verificar la integridad de los contenidos de los textos y su legibilidad es también responsabilidad de los autores. Una vez los artículos o textos que están en edición hayan sido aprobados en su arte final para publicarse, los errores u omisiones serán responsabilidad de los autores.

\section{Distribución y acceso}

Cada autor recibirá dos ejemplares de obsequio del número en el que se publicó el artículo. Igualmente, la versión digital del artículo y del número completo estará disponible para uso del autor, con el fin de que apoye su difusión entre el público objetivo.

Ingeniería Solidaria sigue una política de acceso abierto y buscará la mayor cantidad de canales y estrategias posibles para que las ediciones que publica sean visibles para una audiencia amplia (nacional e internacional). No obstante, los autores deben tener claro que el impacto de la difusión de su artículo recae en buena medida en su participación activa en el proceso. Se espera que los mismos autores remitan la versión digital del artículo a investigadores del área de sus países y en el extranjero, además de estimular su uso como apoyo bibliográfico en procesos de investigación y escritura entre sus colegas, o propiciando su consulta en el aula de clase entre estudiantes de pregrado, maestría y doctorado.

Por otra parte, la circulación de la revista y su venta se realizará de acuerdo con las políticas y canales que establezca la Editorial de la Universidad Cooperativa de Colombia para tal fin.

\section{Nota legal}

Las perspectivas o puntos de vista expresados en los artículos y textos que publica Ingeniería Solidaria son responsabilidad de sus autores y no comprometen en ninguna medida a la revista, a la Editorial o a la Universidad Cooperativa de Colombia. Asimismo, el propósito fundamental de la revista es prestar un servicio a la comunidad académica y al avance del conocimiento en las ingenierías, por lo que el proceso de selección del material que publica contempla aspectos académicos, editoriales y legales que son evaluados en cada caso para decidir sobre los manuscritos que se reciben. Supeditada a estos factores, la revista no está obligada a la publicación de ningún texto y podrá declinar su publicación en cualquier fase del proceso, si estima que no corresponde a su línea editorial o si contradice alguna de sus políticas editoriales.

\section{Reproducción y traducciones}

Si usted desea reproducir o traducir un artículo o texto publicado en Ingeniería Solidaria, por favor escriba a los correos electrónicos de la revista (ingenieriasolidaria@ucc.edu.co). Los textos publicados en la revista, no obstante, no requieren una autorización especial para que sean consultados, descargados o se hagan enlaces al sitio web de la revista desde páginas personales, institucionales o repositorios. 


\section{Authors guidelines}

http://ingenieriasolidaria.ucc.edu.co

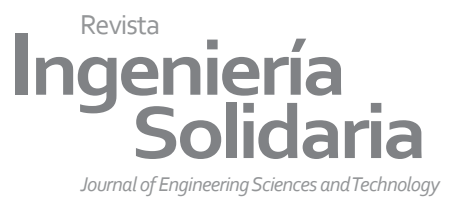

documents that have already been published the work will be automatically rejected.

Selection system. All the articles presented to the journal shall be submitted to a "double blind" selection process that will be carried out with the help of expert peer reviewers on each subject. The participation of reviewers will be made ad honorem, and we expect it to be assumed as an act of scholarly reciprocity seeking to collaborate in a constructive manner to strengthen (and validate) the research and contributions of other colleagues within the field. In the case of reviews, which are diffusion documents, they may be checked by the editor himself or by other members of the editorial team of the journal. Their publication will be decided based on their thematic and textual coherence, their relevance for the field, or according to the relevance of the proposed discussion.

Exclusiveness. The articles submitted to Ingeniería Solidaria cannot be in a selection process in other journals, nor should they be presented at other publications while they are under evaluation.

Confidentiality. Since the selection is made through a "double blind" system, seeking to warranty the independence of the parts (neither the author nor the reviewers will have access to each other's identity, profile or origin), this information shall be treated solely by the people in charge of the journal and will not be revealed to third parties. The support of the process for each article will be kept for indexation purposes or for review verification.

Profile of the evaluators. The peers of Ingeniería Solidaria will have at least a master's level and published production in the area on which they will be asked to review texts.

Periodicity. Ingeniería Solidaria is a four-month journal (January, May, and September). The journal will also publish special thematic issues following the initiative of the editor, of the members of the committees or of external collaborators, and their publication may be made in extraordinary (additional) issues within the volume (the conditions or particularities for special editions will be divulged through a specific call for papers).

Structure of the articles. The basic structure of an article comprises the following elements: title, abstract, keywords, body of the text (which may vary according to the kind of article or the author's intention) and list of references. The details that an author must take into account to prepare his or her article for Ingeniería Solidaria are more extensively described in a template that has been developed for such an end.

Purpose and Coherence. We expect all articles that are submitted to Ingeniería Solidaria to have an explicit purpose and to seek for such a purpose, a contribution that will be of interest for the public of the journal. Moreover, aside from the possible structure that the author may decide to give to the article (review or paper), we expect texts to follow a coherent scheme in which the three essential elements, introduction, articulated development of the topic and closing, are included.

Ethics. The journal and its editorial board will favor, through their policies and actions, ethics in research processes, appropriate use of contents protected by copyrights and quality cept for online publication of working papers - or in translation to other languages. If we detect evidence of similar or identical
Originality. All articles or reviews subjected to the selection process of Ingeniería Solidaria must be unpublished. We request that the authors refrain from sending works that have already been published either partially or whole in other media - ex-

\section{Ingeniería Solidaria is a publication that focuses on the diffusion}

Ingeniería Solidaria will receive critical reviews on monographs, says selected from contests or national scholarly events in which the journal is involved may be published.

\section{Editorial Policies and Presentation Guidelines}


of works published, so that the different collaborators (editors, authors and evaluators) interact under principles of academic integrity.

Authors. Authors participating in the journal are expected to submit unpublished, original texts created by themselves as a result of rigorous research processes and properly use sources serving as bibliographic support and any other material protected by copyrights. Texts must be thoroughly written considering form and citation requirements pertaining to the journal style.

Evaluators. Journal evaluators are expected to do a detailed and constructive reading of each article they accept to review, seeking to not only give a recommendation of approval or rejection to the editor, but also enable authors, through their comments, to improve their texts and reflect on the scope, possibilities or shortcomings of their writings. Additionally, evaluators must consider that the texts entrusted to them by the editor are unpublished, and any improper or unauthorized use of the information contained therein would imply a serious unethical conduct. Moreover, the responsibility of evaluating a work, once accepted, cannot be transferred to third parties, especially if this has not been justified or previously consulted with the editor. Finally, any conflict of interest identified by the evaluator after receiving a work that may undermine their independence in the preparation of an opinion must be informed.

Use of contents and self-archiving. The journal publishes its contents in open access, without any embargo period. In addition, all works are published under a Creative Commons' Attribution-NonCommercial-NoDerivatives 4.0 International license (http://creativecommons.org/licenses/by-nc-nd/4.0/), and their use must adhere to these licensing conditions.

Furthermore, authors can self-archive their works in institutional repositories, in the final version (or editor's version) of the article that was published, insofar as bibliographic data of the original article publication are provided to give credit to the journal. At the time of self-archiving a published article, it is also advisable that the authors include a link to the article, through its doi, so that it can be consulted on the official website of the journal. An active role by the authors in disseminating their published work among colleagues, graduate and undergraduate students and, generally, the academic community is key to make a more effective contribution to the discipline or produce greater impact on research and academic training processes.

Submission and processing charges. Both submission and processing of articles (in case of approval) are free of charge in this journal; we do not ask for any fee at any stage of the publishing process. The journal is fully supported by the Universidad Cooperativa de Colombia Press.

Digital preservation of contents. The Editorial Fund will ensure digital preservation of contents published so that authors can always retrieve their articles over time and maintain access to what has been the history and evolution of the journal.

Extension. We suggest that articles have a minimum extension of four thousand $(4,000)$ words and a maximum of eight thousand $(8,000)$. Critical reviews should not exceed fifteen hundred $(1,500)$ words.

Languages. Ingeniería Solidaria will publish whole articles originally written in Spanish, English or Portuguese.
Submission. The article proposals must be submitted in Word format, adjusting the text to the template and only through electronic means. Together with the article, each of the authors must send a fully filled out author card and a letter of originality and ethical commitment. The original file and the attachments must be sent to the editor of the journal at: ingenieriasolidaria@ ucc.edu.co. The reviews will also be accepted through this medium exclusively following the corresponding template.

\section{Quotation style: IEEE}

Quotation styles allow for an organized presentation of the bibliographic support upon which the text is built (in its antecedents, arguments, methodology, etc.), and they facilitate the location and direct consult of said sources. In the case of Ingeniería Solidaria, we have selected the standards designed by the Institute of Electrical and Electronics Engineers identified with the acronym IEEE that are commonly used in engineering publications.

We cite hereunder some aspects that must be taken into account concerning the use of the IEEE Rules as well as some particularities incorporated by the journal.

Body of the text. Even though the IEEE Rules do not mandate that the author of a source be mentioned when the reference is made within the body of the text, Ingeniería Solidaria, in order to avoid grammar or writing mistakes, prefers that in such cases the last names of the authors whose ideas are being cited be mentioned, and to insert afterwards the reference number between square brackets. For instance: "Ortiz [1] presents a methodology for the analysis of this kind of problem". All references that are incorporated in the body of the text must appear in the reference list at the end of the article. Moreover, the reference list should not include bibliography that was not used and quoted within the text (that is, the quoted works must correspond exactly to what appears in the list). The references incorporated in the text must be enumerated according to the order of appearance between square brackets-Ortiz [1], Grothendieck [2], Gómez [3]—, and must be organized in the same order in the final list, not in alphabetical order. Lastly, if the same reference is used more than once in the body of the text but it is necessary to incorporate additional information about where in the text the reference is or any other particularity, this must be indicated after the reference number in the following way: "Ortiz[1, p.84] or Ortiz [1, Fig.16]".

List of references. The list of references must be organized by numerical order determined by the order of appearance of each reference within the text (the first quoted author or work is [1], the second [2] and so on). Since, unlike other citation systems, this one does not organize references alphabetically, the names of the authors must be listed starting by the initials of the first name followed by the last name "[2] A. Grotendieck". Below, we will show the template to reference a book, a chapter of a book and an article in a journal, with some examples for each case:

\section{Book}

[\#] Initials. Last name, Title of book. City: Editorial, year, pp. Example: [1] R.H. Ballou, Businees Logistics: Supply Chain Management. New York: Prentice Hall, 2003, pp 250-300.

\section{Book chapter}

[\#] Initials. Last name, "Title of chapter", in Title of book, number of edition. Name of the editor, Ed. City: Editorial, year, pp. (range of pages). 
Example: [1] R. Anderson, "Access control", in Security Engineering, 2nd ed. New York: Wiley, pp. 93-128.

\section{Journal Article}

[\#] Initials. Last name, "Title of article", Title of journal, vol., n. ${ }^{\circ}$, pp. (range of pages), abbrev. month. Year.

Example: [1] S. Zhang, C. Zhu, J. K. O. Sin \& P. K. T. Mok, "A novel ultrathin elevated channel low-temperature poly-SI TFT", IEEE Electron Device Lett, vol. 20, pp. 569-571, Nov. 1999.

Should you need additional examples to quote other kinds of texts please contact the editor or consult the IEEE page that describes the style of the IEEE Rules: http://www.ieee.org/publications_standards/publications/authors/authors_journals.html

\section{Graphical aspects and other particularities}

Equations, graphs, tables and figures. Mathematical expressions must be typed using an adequate formulae editor. Special symbols should be defined the first time they appear, be it in figures, tables or text. Each table, figure or graph must indicate its source (or if it is the author's own creation), listing the reference with the corresponding number. Graphs figures and tables must always be supplied in an editable format (we recommend Excel). In the case of photographs or images, these must be sent in at least $350 \mathrm{dpi}$, on .jpg file extension and the authors must certify that they have the permission to use them or reproduce them.

Nomenclature, abbreviations and symbols. Ingeniería Solidaria will request the use of the International System of Units (sI) and the corresponding symbols.

\section{Article Selection Process}

As we mentioned before, Ingeniería Solidaria follows a "double blind" system to evaluate and decide on the publication of its main articles. We list below the stages of this process in a more detailed manner:

Reception and editorial evaluation. Once the editor receives the submission of the article, a notification will be sent to the author confirming the submission. Afterwards, the editor will carry out a preliminary review of the article to see if it complies with the presentation parameters for the journal and if it corresponds to the editorial and thematic guidelines. The editor holds the power to decide whether the article can be evaluated for selection or if it should be rejected on this first step. In this phase the editor may also return the text to the authors, requesting some corrections or clarifications before it can be sent to the official selection process. In such case, the authors must resubmit the article with the demanded corrections (or the documentation that may be missing such as the author card or commitment letter) if they wish to continue the process.

Peer selection. If the article is admitted for the selection process the editor will set to assign reviewers, locating and convoking two expert researchers on the area of the article. The reviewers will then receive the full text of the article and a format that will guide them through the process.

Selection time. The usual length of a complete selection cycle (location of peer reviewers, invitation and acceptance, reception of the judgments, delivery to the authors) must not exceed a trimester. However, it is relatively difficult to find adequate and willing peers on some topics so the timeframes will be negotiated directly with each reviewer considering their availability (and seeking to carry out the process in the most efficient way possible).
Results. The editor will send a result to the authors based on the judgment of at least two peer reviewers. In case the judgments of both reviewers are in conflict (an acceptance and a rejection), we will call a third reviewer before the editor can inform the authors of the results. The results of the selection process can be: "approved without modifications", "approved with minor modifications", "approved with mayor modifications" or "rejected". The "approved with mayor modifications" is equivalent to "revise and resubmit", which implies that the authors must be willing to restate their proposal. Should the authors not be willing to carry out the modifications, the selection process will be over and the authors will be free to submit their work to another publication.

Corrections. Along with the results, should the editor consider that it is necessary to have a corrected version of the article, he will accord a deadline with the authors for the submission of such a version. This deadline oscillates between 2 and 10 weeks, the last in case a substantial adjustment is needed. If the authors fail to comply with the stipulated deadlines, the editor may end the process for the article, thus preventing it from being published. To help with the review of the corrected version authors must use the word change-tracking feature and send a letter to the reviewers explaining the adjustments that were carried out. Without this response the editor will not send the adjusted article for verification.

Verification and final version. The verification will be carried out with the help of the peer reviewers in most cases but the editor can also check the adjustments in case they were minor corrections. Thus, should slight corrections be requested for an article, we ask the authors to refrain from incorporating mayor changes or changes that imply conceptual or methodological adjustments that have not been asked by the reviewers. Should the adjustments be satisfactory, the editor will inform the authors of the approval and will request the presentation of the final version of the article in a template that shall be sent to editorial production. Should a significant error, requiring substantial changes, be found in preparing the final version, the editor must be informed.

\section{Publishing process}

The articles and the different kinds of texts that might be approved for publication in an issue of Ingeniería Solidaria will be subject to a professional publishing process that comprises the following stages: style correction, diagramming, proofreading, verification, and final approval of arts.

The authors must submit the manuscript that was approved for publication in a template that will be provided by the journal, making sure to comply with all the instructions therein. In addition, authors are responsible to attend to the observations, clarifications or corrections that may arise during the publishing process within the concrete deadlines that will be set so as to avoid delays in the publication.

It is also the responsibility of the authors to verify de legibility and integrity of the contents of the texts. Once the texts have been approved in their final art for publication, any mistakes or omissions will be the sole responsibility of the authors.

\section{Distribution and access}

Every author shall receive two copies of the issue in which the article was published. Moreover, the digital version of the article and of the whole issue will be available for the author's use so that he may support its diffusion among the target audience. 
Ingeniería Solidaria follows an open access policy and will seek as many channels and strategies as possible so that the published issues may be visible by a large (national and international) audience. However, the authors must know that the impact of the diffusion of their articles relies heavily on their active involvement in this process. We expect authors themselves to forward the digital versions of their articles to researchers on the area, be it in their countries or abroad, and that they stimulate their use as bibliographic support in research and writing processes in among their colleagues or promoting its reading in class for undergraduate or graduate students.

\section{Legal Note}

The perspectives or viewpoints expressed in the articles and texts published by Ingeniería Solidaria are the sole responsibility of their authors, and do not commit in any measure the Journal, the Editorial or the Universidad Cooperativa de Colombia. Moreover, the main purpose of the journal is to provide a service for the academic community and for the advancement of knowledge on Engineering and thus the selection process for the published material contemplates academic, editorial and legal aspects that are evaluated for every single case to decide about the submitted manuscripts. Since it is dependent on these factors, the journal is not obliged to publish any text and may decline publication at any moment during the process if it deems that the article does not correspond to its guidelines or fails to comply with any of its editorial policies. Similarly, any reclamation made by third parties concerning the use of works or excerpts in an article or text will be the full responsibility of the authors, thus exempting the Universidad Cooperativa de Colombia.

\section{Reproduction and translations}

If you wish to reproduce or translate an article or text published in Ingeniería Solidaria, or if you want to ask for authorization to divulge it in a web page or institutional repository please write an email to ingenieriasolidaria@ucc.edu.co addressed to the editor. Nonetheless, texts that are published in the journal do not require special authorization to be viewed, downloaded or linked to the website of the journal from personal or institutional pages, or repositories. 